\title{
Non-invasive tests for the prediction of post- hepatectomy liver failure in the elderly
}

\author{
Giovanni Marasco ${ }^{1}$, Antonio Colecchia², Matteo Milandri ${ }^{3}$, Benedetta Rossini ${ }^{1}$, Luigina Vanessa Alemanni ${ }^{1}$, \\ Elton Dajti ${ }^{1}$, Federico Ravaioli ${ }^{1}$, Matteo Renzulli ${ }^{3}$, Rita Golfieri ${ }^{3}$, Davide Festi ${ }^{1}$
}

'Department of Medical and Surgical Sciences (DIMEC), University of Bologna, Bologna 40138, Italy.

${ }^{2}$ Unit of Gastroenterology, Borgo Trento University Hospital of Verona, P.le Aristide Stefani 1, Verona 37126, Italy.

${ }^{3}$ Radiology Unit, Sant'Orsola Malpighi Hospital, Bologna 40138, Italy.

Correspondence to: Dr. Antonio Colecchia, Unit of Gastroenterology, Borgo Trento University Hospital of Verona, P.le Aristide Stefani 1, Verona 37126, Italy. E-mail: antonio.colecchia@aovr.veneto.it

How to cite this article: Marasco G, Colecchia A, Milandri M, Rossini B, Alemanni LV, Dajti E, Ravaioli F, Renzulli M, Golfieri R, Festi D. Non-invasive tests for the prediction of post-hepatectomy liver failure in the elderly. Hepatoma Res 2020;6:32.

http://dx.doi.org/10.20517/2394-5079.2019.54

Received: 30 Dec 2019 First Decision: 16 Mar 2020 Revised: 5 May 2020 Accepted: 21 May 2020 Published: 18 Jun 2020

Science Editor: Bruno Nardo Copy Editor: Cai-Hong Wang Production Editor: Tian Zhang

\begin{abstract}
Post-hepatectomy liver failure (PHLF) is associated with great morbidity and mortality after resection of hepatocellular carcinoma. Previous studies have underlined that advanced age could be a potential factor influencing post-operative complications and long-term survival.

In the past, candidates for resection were based on the Child-Pugh classification, the predictive value of which was rather low. The selection of patients undergoing resection in Western countries is based on the assessment of portal hypertension $(\mathrm{PH})$, which is clinically assessed by measurement of the hepatic venous pressure gradient, an invasive and costly process. Thus, there have been several attempts to identify the best non-invasive test (NIT) to accurately predict PHLF. Most biochemical NITs for the prediction of PHLF are focused on evaluation of underlying liver cirrhosis and PH. Amongst them, FIB-4, which also includes the patient's age, seems to have more robust supporting results. In Europe and the USA., the most tested and reliable NIT for predicting PHLF is the evaluation of liver stiffness measurement, which is also influenced by age. Imaging parameters are promising tools which are used only in specialized centers however, and when available. Liver volume parameters, as well as contrastenhanced data, demonstrate good accuracy in predicting PHLF. In this scenario, the evaluation of sarcopenia and bone mineral density through contextual imaging allows the delineation of PHLF in at-risk elderly patients. Further studies focused on parameters for the evaluation of PHLF in elderly patients are needed.
\end{abstract}

Keywords: Post-hepatectomy liver failure, liver resection, elderly, liver stiffness measurement, indocyanine green retention test

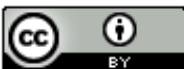

(C) The Author(s) 2020. Open Access This article is licensed under a Creative Commons Attribution 4.0 International License (https://creativecommons.org/licenses/by/4.0/), which permits unrestricted use, sharing, adaptation, distribution and reproduction in any medium or format, for any purpose, even commercially, as long as you give appropriate credit to the original author(s) and the source, provide a link to the Creative Commons license, and indicate if changes were made. 


\section{INTRODUCTION}

Hepatocellular carcinoma (HCC) is the most common cause of death in patients with cirrhosis ${ }^{[1]}$. Despite numerous therapeutic options, the only curative treatments are liver transplantation and hepatectomy ${ }^{[2]}$. Patients with a single HCC nodule, Child-Pugh class A, normal bilirubin $(<1 \mathrm{mg} / \mathrm{dL})$ and without portal hypertension have the best prognosis and are ideal candidates for liver resection.

The presence of clinically significant portal hypertension (CSPH) (port-hepatic pressure gradient greater than $12 \mathrm{mmHg}$ ) or clinical manifestation (platelet count $<100,000 / \mathrm{mL}$, associated with splenomegaly or esophageal varices) appears to be associated with a worse prognosis, but does not preclude resection in selected patients ${ }^{[3,4]}$. Thus, patients with cirrhosis should be carefully selected to reduce the risk of postoperative liver failure and death. Post-hepatectomy liver failure (PHLF) is still a major concern for liver surgeons ${ }^{[2]}$. In the last few years, there has been an increasing need for a simple and accurate tool for evaluating liver function before surgery to minimize PHLF and postoperative mortality ${ }^{[5]}$. It is difficult to define PHLF exactly since it manifests with one or more of these features: ascites, jaundice, coagulopathy or kidney failure. The most commonly used criteria for defining PHLF are the 50-50 Criteria where PHLF is defined as total serum bilirubin $>50 \mathrm{mmol} / \mathrm{L} 5$ days after surgery or thereafter and an international normalized ratio (INR) $>1.7^{[6]}$. Other diagnostic criteria are the peak bilirubin $>7 \mathrm{mg} / \mathrm{dL}$ in any postoperative period, in the absence of cholestasis, and the International Study Group of Liver Surgery (ISGLS) criteria that define PHLF by an increased INR and concomitant hyperbilirubinemia on or after postoperative day $5^{[7]}$.

In the past, the selection of candidates for resection was based on the Child-Pugh classification but its predictive value has been determined to be insufficient. Japanese groups use the indocyanine green retention test (ICG), which has proved to be more reliable than Child-Pugh and the Model for End-stage Liver Disease (MELD) to predict PHLF ${ }^{[8,9]}$. In Western countries, the selection of candidates for resection is usually based on the assessment of portal hypertension, which is clinically assessed by measurement of the hepatic venous pressure gradient $(\mathrm{HVPG}>10 \mathrm{mmHg})^{[10]}$. However, these methods are invasive and costly. Thus, several authors have tried to evaluate other non-invasive methods including biochemical scores, the measurement of liver and spleen stiffness (LSM and SSM) and imaging patterns as predictors of PHLF ${ }^{[8,11-14]}$.

With an increase in life expectancy and improvement in operative safety and efficacy of hepatic resection techniques, surgeons should also evaluate the best surgical option in elderly patients ${ }^{[15]}$. Indeed, previous studies have implicated older age as a potential factor influencing post-resection complications and survival, and are summarized in a recent systematic review and meta-analysis ${ }^{[15]}$ which concluded that age $>70$ was associated with increased 30-day and overall mortality when compared with non-elderly cohorts. A promising factor that also influences post-operative outcomes is patient frailty, defined as a syndrome characterized by decreased physiological reserves. Only one study has reported a specific association between frailty and $\mathrm{PHLF}^{[16]}$. However, frailty assessment is based on a self-reporting questionnaire, which could be affected by several biases.

Thus, this review aims to summarize the recent advances on objective parameters such as non-invasive tests (NITs) for predicting PHLF, particularly in elderly patients.

\section{BIOCHEMICAL SCORES}

\section{Fibrosis and liver functional reserve scores}

FIB-4

The Fibrosis (FIB)-4 index was first proposed by Sterling and colleagues ${ }^{[17]}$ and is based on four factors included in the following equation: [age(years) $\times \mathrm{AST}(\mathrm{UI} / \mathrm{L})$ / platelet count $\times \mathrm{ALT}(\mathrm{UI} / \mathrm{L})$ ]. It is a non- 
invasive predictor of the progression of fibrosis in patients with chronic viral hepatitis. Over the years, several studies have validated its role as a marker of hepatic fibrosis ${ }^{[18,19]}$.

An important study ${ }^{[20]}$ indicated that the Fib-4 index not only demonstrated the best predictive ability for cirrhosis, but it was also an independent prognostic factor for postoperative hepatic insufficiency, overall survival, and disease-free survival for HCC patients with radical liver resection. They also stratified patients, with the cut-off value of 3.15, into Low and High fibrosis-4 groups. The High fibrosis-4 group had a higher mean age $(56.3 \pm 10.4$ vs. $47.7 \pm 11.7, P<0.01)$, higher MELD score $(P=0.001)$, and more patients with Child-Pugh grade B $(7.4 \%$ vs. $4.0 \%, P=0.037)$.

These results have also been confirmed by other studies ${ }^{[21]}$. Other groups have tried to use the ratio of the remaining liver volume (FLRVR) and FIB-4 to predict PHLF and showed that FLRVR/FIB-4 was an independent predictive factor of outcomes after liver resection in cirrhotic patients ${ }^{[22]}$. The most recent study by Zhou et al. ${ }^{[23]}$ demonstrated that the FIB-4 index was a more accurate predictive factor for PHLF and survival than the Child-Pugh score; the authors thus proposed the use of the FIB-4 index to perform pre-hepatectomy assessment citing a low incidence of PHLF in patients with FIB- $4 \leq 4.16$. On the other hand, Zhang et al. ${ }^{[24]}$ showed that FIB-4 was an independent predictor of PHLF only in minor hepatectomy patients. Multivariate analysis in this subgroup of patients revealed that age (the older the patient, the more the risk), Child-Pugh score and Albumin-Bilirubin score/spleen thickness ratio (ALBI/ST) were predictors of PHLF in the APRI model, while Child-Pugh score, FIB-4, and ALBI/ST were found to be significant risk factors of PHLF in the FIB-4 model. Thus, it is possible to conclude that FIB-4 is able to predict PHLF since it is related not only to the degree of liver fibrosis but also, to the general performance of the patient since it includes age.

\section{Lok Index and Forns Index}

The Lok Index and Forns Index are two other non-invasive markers of fibrosis. The Lok index is a noninvasive tool introduced by an American research group ${ }^{[25]}$ as a predictor of cirrhosis development in patients with chronic HCV-hepatitis. It is based on simple laboratory parameters and calculated through the following formula: $\log$ odds (predicting cirrhosis) $5.56-0.0089 \times$ platelet count $\left(\times 10^{3} / \mathrm{mm}^{3}\right)+1.26 \times$ AST/ALT ratio + $5.27 \times$ INR. Some studies have correlated the value of the Lok index with the grade of fibrosis. For example, Ma et al. ${ }^{[26]}$ showed that FIB-4 and Lok's model were the most effective models for distinguishing significant and extensive fibrosis. Zhou et al. ${ }^{[27]}$ found that a Lok index cut-off value of 0.4531 could further spare $24.2 \%$ of gastroscopies without missing high-risk varices $(\mathrm{HRVs})^{[27]}$. Since this is a fibrosis marker, Mobarak et al. ${ }^{[28]}$ found that it was also able to predict HCC development. To date, the Lok-index is predominantly used for the prediction of fibrosis and cirrhosis but not PHLF.

The Forns Index was developed by Forns et al. ${ }^{[29]}$ in 2002, before the introduction of transient elastography techniques. It was first proposed as a non-invasive tool for the detection of patients with non-significant liver fibrosis. It is calculated using four variables (age, gamma glutamyl transferase, total cholesterol and platelet count) with the following formula: $7.811-3.131 \times \ln$ [platelet count $\left.\left(10^{9} / \mathrm{L}\right)\right]+0.781 \times \ln [$ gamma GT (IU/L)] $+3.467 \times \ln$ [age (years)] $-0.014 \times[$ cholesterol $(\mathrm{mg} / \mathrm{dL})$. The first studies on the Forns Index (FI) highlighted its accuracy in identifying patients with different stages of fibrosis and cirrhosis ${ }^{[2,30]}$. A recent study showed that the Forns index is also useful in evaluating liver functionality and the degree of liver fibrosis, so it is able to predict HCC recurrence and patient survival ${ }^{[31]}$. However, to date, little is known on the use of the Forns index to predict PHLF.

\section{ALBI score}

Another biochemical index used in clinical practice is the Albumin-Bilirubin (ALBI) score, which was introduced by Johnson et al. ${ }^{[32]}$ to evaluate liver function in patients with hepatocellular carcinoma. It was 
Table 1. Studies evaluating ALBI score in predicting PHLF

\begin{tabular}{|c|c|c|c|c|c|c|c|}
\hline Authors & Country & Population & Etiology & Outcome & Nr. cases & ALBI cut-off & AUROC \\
\hline Toyoda et al. ${ }^{[38]}, 2016$ & Asia/Europe & 1,148 & Mixed & Death & $\mathrm{N} / \mathrm{A}$ & -2.60 & $\mathrm{~N} / \mathrm{A}$ \\
\hline Wang et al. ${ }^{[39]}, 2016$ & China & 1,242 & $85 \% \mathrm{HBV}$ & PHLF & 166 & -2.77 & 0.723 \\
\hline Ke et al. ${ }^{[40]}, 2016$ & China & 372 & $80 \% \mathrm{HBV}$ & Postoperative complications & 166 & $N / A$ & 0.721 \\
\hline Andreatos et al. ${ }^{[41]}, 2017$ & USA & 2,659 & $\mathrm{~N} / \mathrm{A}$ & PHLF & 149 & $-2.60 /-1.39$ & $\mathrm{~N} / \mathrm{A}$ \\
\hline Li et al. ${ }^{[42]}, 2017$ & China & 491 & $83 \% \mathrm{HBV}$ & Postoperative complications & 270 & -2.45 & 0.647 \\
\hline Russolillo et al. ${ }^{[43]}, 2019$ & Italy & 400 & $40 \% \mathrm{HCV}$ & $\begin{array}{l}\text { Overall morbidity, } \\
\text { PHLF }\end{array}$ & $\begin{array}{l}176 \\
82\end{array}$ & $-2.60 /-1.39$ & N/A \\
\hline Božin et al. ${ }^{[44]}, 2018$ & Croatia & 38 & $84 \%$ ALD & Death & 24 & N/A & N/A \\
\hline Zhang et al. ${ }^{[5]}, 2018$ & China & 338 & $82 \% \mathrm{HBV}$ & PHLF & 26 & -2.44 & 0.782 \\
\hline Zou et al. ${ }^{[37]}, 2018$ & China & 473 & $85 \% \mathrm{HBV}$ & PHLF & 50 & -2.303 & 0.745 \\
\hline Mai et al. ${ }^{[45]}, 2019$ & China & 1,055 & HBV & PHLF & 151 & -2.77 & 0.717 \\
\hline
\end{tabular}

ALBI: Albumin-bilirubin; ALD: alcoholic liver disease; HBV: hepatitis B virus; HCV: hepatitis C virus; N/A: not available; PHLF: posthepatectomy liver failure

initially proposed as an alternative to the Child-Pugh score, which has some limitations, such as the inclusion of non-objective parameters (ascites, encephalopathy). However, the ALBI score was also able to predict the severity and long-term prognosis of patients with chronic liver disease ${ }^{[33]}$. In particular, it was found to be a reliable prognostic tool in assessing short-term outcomes in hepatic decompensation ${ }^{[34]}$, in predicting inhospital mortality in patients with acute upper gastrointestinal bleeding ${ }^{[35]}$ and as a prognostic factor in HCC patients ${ }^{[36]}$. The ALBI score is based on serum levels of albumin and total bilirubin and can be calculated through the following formula: $(\log 10$ bilirubin $[\mu \mathrm{mol} / \mathrm{L}] \times 0.66)+($ albumin $[\mathrm{g} / \mathrm{L}] \times-0.0852)$. It was further categorized into three different grades: grade $3(>-1.39)$, grade $2(>-2.60$ to $\leq-1.39)$, and grade $1(\leq-2.60)^{[32]}$.

The ALBI grade was also a significant prognostic factor for PHLF in HCC patients ${ }^{[5]}$. In a comparative study ${ }^{[37]}$, the ALBI score showed superior predictive value of PHLF over the Child-Pugh score, MELD score and ICG R15. The area under the ROC curve (AUC) of the ALBI score (AUC 0.745) for predicting PHLF was significantly higher than that of the Child-Pugh score (AUC 0.665), MELD score (AUC 0.649) and ICG R15 (AUC 0.668). With a cut-off value of the ALBI score of -2.303, it was possible to reach a sensitivity of $77.3 \%$ and a specificity of $64.0 \%$ for predicting PHLF $^{[37]}$. Another group ${ }^{[24]}$ associated the ALBI score with spleen thickness (ST) as a surrogate of portal hypertension. In this study, they compared the predictive ability of ALBI/ST with FIB-4 and APRI and found that ALBI/ST had a higher diagnostic accuracy for PHLF than FIB-4 and APRI. The AUC for the ALBI/ST ratio (AUC $=0.774, P<0.001$ ) was larger than that of FIB-4 $($ AUC $=0.696, P<0.001)$, APRI $($ AUC $=0.697, P<0.001)$, ALBI $($ AUC $=0.701, P<0.001)$, and $\mathrm{ST}($ AUC $=$ $0.710, P<0.001)^{[24]}$. Also, in this study, multivariate analysis in the minor hepatectomy subgroup revealed that age, Child-Pugh score and ALBI/ST and Child-Pugh score, FIB-4, and ALBI/ST were significant predictors of PHLF in the APRI and FIB-4 models respectively. However, a study conducted by Zhang et al. ${ }^{[5]}$ showed that the ALBI grade was a good predictor of overall survival in BCLC stage 0/A patients but not in other BCLC stages. Thus, it is possible to conclude that the novel ALBI score is certainly one of the most validated scores for predicting PHLF, as described in Table $1^{[5,33,45,37-44]}$.

\section{Indocyanine Green Retention Test}

The clearance of indocyanine green (ICG) is a test used to assess liver excretory function quantitatively. ICG is a water-soluble fluorescent dye, which totally binds to albumin and $\beta$-lipoprotein in the blood and is exclusively taken up by hepatocytes and excreted unmodified in bile, without entero-hepatic circulation ${ }^{[46,47]}$. Thus, its clearance depends on several factors: hepatic blood flow, the function of the hepatocytes and biliary excretion ${ }^{[46,47]}$. However, this test takes time and is uncomfortable for patients. Thus, a faster sampling method was subsequently introduced, the ICG 15-min retention test (ICG-r15), consisting of an injection of an ICG bolus and peripheral venous blood sampling every $5 \mathrm{~min}$ for $20 \mathrm{~min}^{[48,49]}$. In the last few decades, a noninvasive ICG measurement by spectrophotometry, called LiMON ${ }^{\bullet}$ (Pulsion Medical System, Munich, 
Table 2. Studies evaluating ICG in predicting PHLF

\begin{tabular}{|c|c|c|c|c|c|c|c|c|}
\hline Authors & Country & Population & Etiology & Outcome & Nr. cases & Technique & ICG cut-off & AUROC \\
\hline Kitano et al. ${ }^{[63]}, 1997$ & Japan & 54 & $\mathrm{~N} / \mathrm{A}$ & Hospital mortality & 7 & ICG-r15 & $14 \%$ & $\mathrm{~N} / \mathrm{A}$ \\
\hline Lau et al. ${ }^{[58]}, 1997$ & Hong Kong & 127 & $N / A$ & Death & 14 & ICG-r15 & $\begin{array}{l}14 \% \text { (major hep.) } \\
23 \% \text { (minor hep.) }\end{array}$ & N/A \\
\hline Lam et al. ${ }^{[57]}, 1999$ & Hong Kong & 117 & $N / A$ & $\begin{array}{l}\text { Postoperative } \\
\text { complications }\end{array}$ & N/A & ICG-r15 & $14 \%$ & N/A \\
\hline Hsia et al. ${ }^{[64]}, 2000$ & Taiwan & 168 & Mixed & $\begin{array}{l}\text { Morbidity } \\
\text { Death }\end{array}$ & $\begin{array}{l}51 \\
3\end{array}$ & ICG-r15 & $<10 \% />20 \%$ & $\mathrm{~N} / \mathrm{A}$ \\
\hline Lao et al. ${ }^{[65]}, 2005$ & China & 255 & $\mathrm{~N} / \mathrm{A}$ & Decompensation & $\mathrm{N} / \mathrm{A}$ & ICG-r15 & $10-20 \%$ & $\mathrm{~N} / \mathrm{A}$ \\
\hline Zou et al. ${ }^{[37]}, 2018$ & China & 473 & $85 \% \mathrm{HBV}$ & PHLF & 50 & ICG-r15 & N/A & 0.668 \\
\hline Hwang et al. ${ }^{[66]}, 2015$ & South Korea & 723 & $81 \%$ HBV & Death from PHLF & 6 & FRL-kICG & $<0.05$ & $\mathrm{~N} / \mathrm{A}$ \\
\hline Wang et al. ${ }^{[8]}, 2018$ & China & 185 & $83 \% \mathrm{HBV}$ & Severe PHLF & 23 & ICG-r15 & $7.1 \%$ & 0.724 \\
\hline Kim DKet al. ${ }^{[67]} 2018$ & $\begin{array}{l}\text { South } \\
\text { Korea }\end{array}$ & 73 & Mixed & PHLF & 18 & ICG-PDR & N/A & 0.748 \\
\hline Wang et al. ${ }^{[68]}, 2019$ & China & 35 & Mixed & $\begin{array}{l}\text { PHLF } \\
\text { Day 1-3-5 }\end{array}$ & 16 & $\begin{array}{l}\text { Intra- } \\
\text { operative } \\
\text { ICG-r15 }\end{array}$ & $\begin{array}{l}13.8 \%(\text { day } 1) \\
13.8 \%(\text { day } 3) \\
22.7 \% \text { (day } 5)\end{array}$ & $\begin{array}{l}0.540 \\
0.800 \\
0.910\end{array}$ \\
\hline
\end{tabular}

ICG: Clearance of Indocyanine green; ICG-r15: ICG 15 min retention test; FRL-kICG: ICG constant fraction of future remnant liver; ICGPDR: ICG-plasma disappearance rate; hep: hepatectomy; HBV: hepatitis B virus; N/A: not available; PHLF: post-hepatectomy liver failure

Germany), was developed. The device uses a finger optical probe, which detects, after ICG infusion, the fractional pulsatile changes in optical absorption. The device has already been validated in several studies ${ }^{[50,51]}$ with good correlation with ICG-r15 results, comparable with correction of a mathematical formula ${ }^{[50]}$.

Since ICG clearance depends on blood flow, it was associated with portal hypertension ${ }^{[48]}$ and liver function for its pharmacokinetics (uptake and excretion through the hepatocytes) as well ${ }^{[47,52-54]}$. Thus, in Eastern countries it is considered an accurate method to assess liver functional reserve pre-operatively and has been used for almost 30 years ${ }^{[47]}$; on the other hand, in Western countries, it is not widely used because it is highly influenced by hepatic blood flow ${ }^{[47]}$ and thus, by other conditions that could affect it.

The normal ICG-r15 value is about $10 \%{ }^{[55]}$. The ICG-r15 reported cut-off for performing a safe major hepatectomy is between $14 \%$ and $17 \%$, the latter in younger patients with milder liver disease ${ }^{[56,57]}$. Other authors have reported different cut-offs of $14 \%$ and $23 \%$ for safe major and minor hepatectomy respectively ${ }^{[5,58]}$. In another previous study ${ }^{[57]}$ with age and sex-matched patients, the authors found no difference in terms of PHLF and mortality between patients with ICG-r15 of more than, and less than $14 \%$ who have undergone major hepatectomy. However, to date, the reported upper limit of ICG-r15 for considering liver resection is $40 \%{ }^{[59]}$. The accuracy of ICG-r15 in predicting PHLF could be increased with the combination of bilirubin levels and ascites ${ }^{[59]}$. Several authors comparing the performance of ICG-r15 with other parameters found that it was superior to $\operatorname{MELD}^{[60]}$ and that the combination with platelet count, portal hypertension (ICG-r15 cut-off value of $7.1 \%$, sensitivity $52.2 \%$ and specificity $89.5 \%)^{[8]}$ and ChildPugh stage ${ }^{[61]}$ was able to improve its accuracy. Moreover, liver stiffness measurement (LSM) was also found to correlate with ICG-r15 and to provide additional information on the prognosis of the patient ${ }^{[62]}$. Other authors have found good correlation when comparing ICG-r15 with the degree of portal hypertension ${ }^{[48,54]}$.

In conclusion, no definitive lower ICG-r15 cut-offs for distinguishing between safe minor or major hepatectomy are currently available, as shown in Table $2^{[8,37,57,58,63-67]}$; major hepatectomy in the presence of unsatisfactory ICG-r15 results should be performed only in high-volume centers. ICG-r15 could be considered a good marker of liver function and indirectly, of the degree of portal hypertension. Further studies are needed however, for this latter association.

\section{Portal hypertension scores}

Plated to spleen stiffness ratio PSR

Another widely used biochemical score is the PSR (platelet count-to-spleen ratio), which consists of the ratio between PLT (expressed in number $/ \mathrm{mm}^{3}$ ) and spleen diameter $(\mathrm{mm})^{[69]}$. The PSR value is strictly 
correlated with the degree of portal hypertension and, since it was first proposed, this score has shown good performance in predicting the development of esophageal varices in cirrhotic patients ${ }^{[69-71]}$. A recent Chinese study $^{[72]}$ evaluated the accuracy of PSR, calculated using platelet count and spleen volume (expressed in $\mathrm{mm}^{3}$ ), as a diagnostic index for the stage of liver fibrosis in patients with HCC and compared PSR with other currently-used scores. Among patients with severe fibrosis, AUROC was significantly higher for PSR (0.808) than for other NITs, except for APRI $(0.739, P=0.215)$. Peng et al ${ }^{[12]}$, instead, conducted a study on the risk factors for PHLF in which they used, among various markers, a variant of PSR based on spleen stiffness measurement (SSM), instead of the spleen diameter or volume. On multivariate analysis, PSR seemed to be an independent prognostic index for the development of hepatic decompensation $(P<0.001$, odds ratio [OR] $=0.622$, 95\%CI: 0.493 0.784). The PSR thus represents a promising prognostic index for the post-resection outcome.

\section{APRI score}

The APRI score (aspartate aminotransferase [AST] to platelet ratio index) was introduced in a study by Wai et al. ${ }^{[73]}$ and can be calculated using the following formula: AST(UI/L) $\times\left[100 /\left(\right.\right.$ platelet count $10^{3} /$ $\left.\mathrm{mm}^{3}\right)$ ]. It was developed as a non-invasive predictor for progression of fibrosis in patients with chronic viral hepatitis. In 2019, a study by Mai et al. ${ }^{[74]}$ found that the APRI score (AUC 0.743, 95\%CI: 0.706-0.780; $P<0.001)$ had greater accuracy for predicting PHLF than the Child-Pugh, MELD and ALBI scores in the entire cohort of patients with HCC. The APRI-score cut-off value of 0.55 was able to reach a sensitivity of $72.2 \%$ and a specificity of $68.0 \%$ on PHLF prediction. However, Zhang et al. ${ }^{[24]}$ observed that the APRI score showed a predictive significance only in the major hepatectomy subgroup. The Chinese group of Mai et al. ${ }^{[45]}$ used a new combination of ALBI and APRI scores with the following formula: ALBI-APRI score $=5.280 \times$ ALBI $+1.583 \times$ APRI. The AUC of the ALBI-APRI model (AUC 0.766, 95\%CI: 0.739-0.791) for predicting the risk of PHLF was significantly higher than the single ALBI $(P<0.001)$ or APRI scores $(P=0.047)$. The ALBI-APRI score cut-off value of -13.10 had a sensitivity of $78.1 \%$ and a specificity of $62.2 \%$ for predicting the risk of PHLF ${ }^{[45]}$. Thus, the APRI score in combination with other NITs could represent a good surrogate of portal hypertension and should be further investigated for predicting PHLF.

\section{LSPS}

The LSPS (LSM-spleen to platelet ratio score) is a biochemical index derived from the following formula: $\operatorname{LSM}(\mathrm{kPa}) \times\left[\right.$ spleen diameter $(\mathrm{mm}) /$ platelet count $\left.\left(10^{3} / \mathrm{mm}^{3}\right)\right]$. This score was first proposed as a predictive tool for high-risk esophageal varices in patients with HBV-related cirrhosis ${ }^{[75]}$. In a study by Chon and colleagues $^{[76]}$, LSPS was found to be an independent risk factor for both HCC $(\mathrm{HR}=1.001)$ and hepatic decompensation $(\mathrm{HR}=1.002)$ in patients with HBV-related hepatitis. Only a single report on 38 patients highlighted a potential predictive role of LSPS on univariate analysis ${ }^{[77]}$. However, not much is known about the role of LSPS in predicting PHLF.

\section{Other liver function tests}

Over time, other tests for estimating liver function have been developed. These tests use different substrates such as lidocaine, galactose, aminopyrine, amino acid, and methacetin. However, none have been shown to be superior to the ICG clearance test in the prediction of PHLF ${ }^{[55]}$. Other tests are based on the liver's energy production (arterial ketone body ratio; AKBR) and the number of receptors for asialo-glycoprotein (ASGP-R; technetium-99m-galactosyl human serum albumin; 99mTc-GSA scan) but they are expensive and less common than ICG $^{[55]}$. Of course, in the pre-operative assessment, other well-validated tools such as the Child-Pugh and MELD scores continue to be considered. Both have been used widely to predict the outcomes of cirrhotic patients in many different contexts; they showed similar prognostic significance in most cases, even with slight differences in accuracy due to specific settings, as described in a recent, comprehensive meta-nalysis ${ }^{[78]}$. However, as described above, nowadays several NITs (such as FIB- $4^{[23]}$, APRI score $^{[74]}$, ALBI score $e^{[37,39,41,42]}$ or ICG-r $15^{[8]}$ ) appear to be better predictors of PHLF, and warrant further study. 
Table 3. Studies evaluating LSM by elastography in predicting PHLF

\begin{tabular}{|c|c|c|c|c|c|c|c|c|}
\hline Authors & Country & Population & Etiology & Outcome & Nr. cases & Technique & LSM cut-off & AUROC \\
\hline Kim et al. ${ }^{[83]} 2008$ & South Korea & 72 & $83 \% \mathrm{HCV}$ & PHLF & 7 & $\mathrm{TE}$ & $25.6 \mathrm{kPa}$ & 0.824 \\
\hline Cescon et al. ${ }^{[84]} 2012$ & Italy & 90 & $66 \% \mathrm{HCV}$ & PHLF & 26 & TE & $15.7 \mathrm{kPa}$ & 0.865 \\
\hline Harada et al. ${ }^{[85]} 2012$ & Japan & 50 & $68 \% \mathrm{HCV}$ & Ascites & 19 & ARFI & $1.68 \mathrm{~m} / \mathrm{s}$ & 0.900 \\
\hline Wong et al. ${ }^{[86]} 2013$ & China & 105 & $67 \% \mathrm{HBV}$ & Major complications & 15 & $\mathrm{TE}$ & $12 \mathrm{kPa}$ & 0.790 \\
\hline Zhang et al. ${ }^{[87]} 2015$ & China & 75 & HBV & $\begin{array}{l}\text { Ascites } \\
\text { PHLF }\end{array}$ & $\begin{array}{l}13 \\
4\end{array}$ & $\mathrm{TE}$ & $\begin{array}{l}15.6 \mathrm{KPa} \\
14.3 \mathrm{KPa}\end{array}$ & $\begin{array}{l}0.902 \\
0.915\end{array}$ \\
\hline Nishio et al. ${ }^{[88]} 2016$ & Japan & 177 & Mixed & PHLF B or C & 21 & ARFI & $1.61 \mathrm{~m} / \mathrm{s}$ & 0.780 \\
\hline Cucchetti et al. ${ }^{[11]} 2017$ & Italy & 202 & $64 \% \mathrm{HCV}$ & PHLF & 60 & $\mathrm{TE}$ & $\mathrm{N} / \mathrm{A}$ & $\mathrm{N} / \mathrm{A}$ \\
\hline Chong et al. ${ }^{[89]} 2017$ & China & 255 & $82 \% \mathrm{HBV}$ & PHLF B or C & 46 & $\mathrm{TE}$ & $\begin{array}{l}11.5 \mathrm{kPa} \\
20 \mathrm{kPa}\end{array}$ & $\begin{array}{l}0.650 \\
0.825\end{array}$ \\
\hline Han et al. ${ }^{[90]} 2017$ & China & 77 & $90 \% \mathrm{HBV}$ & PHLF & 27 & 2D-SWE & $6.9 \mathrm{kPa}$ & 0.843 \\
\hline Abe et al. ${ }^{[91]} 2017$ & Japan & 175 & Mixed & Major complications & 28 & MRE & $5.3 \mathrm{kPa}$ & 0.810 \\
\hline Shen et al. ${ }^{[92]} 2017$ & China & 280 & HBV & PHLF & 55 & 2D-SWE & $11.8 \mathrm{kPa}$ & 0.720 \\
\hline Rajakannu et al. ${ }^{[93]} 2017$ & France & 106 & Mixed & Decompensation & 9 & TE & $22 \mathrm{kPa}$ & 0.810 \\
\hline Donadon et al. ${ }^{[94]} 2017$ & Italy & 340 & Mixed & Complications & 95 & $\mathrm{TE}$ & $9.7 \mathrm{kPa}$ & 0.728 \\
\hline Wu et al. ${ }^{[95]} 2017$ & China & 54 & $65 \% \mathrm{HBV}$ & PHLF & 7 & $\mathrm{TE}$ & $16.2 \mathrm{kPa}$ & 0.760 \\
\hline Lei et al. ${ }^{[96]} 2017$ & China & 247 & HBV & PHLF & 37 & $\mathrm{TE}$ & $14 \mathrm{kPa}$ & 0.860 \\
\hline Hu et $a l . .^{[97]} 2018$ & China & 216 & $88 \% \mathrm{HBV}$ & PHLF & 64 & SWE & $N / A$ & 0.850 \\
\hline Sato et al. ${ }^{[98]} 2018$ & Japan & 96 & Mixed & Major complications & 15 & MRE & $4.3 \mathrm{kPa}$ & 0.813 \\
\hline Procopet et al. ${ }^{[99]} 2018$ & Romania & 51 & $65 \%$ Viral & $\begin{array}{l}\text { Decompensation } \\
\text { PHLF }\end{array}$ & $\begin{array}{l}15 \\
20\end{array}$ & $\mathrm{TE}$ & $\begin{array}{l}13.6 / 21 \mathrm{kPa} \\
\mathrm{N} / \mathrm{A}\end{array}$ & $\begin{array}{l}0.780 \\
\text { NS }\end{array}$ \\
\hline
\end{tabular}

ARFI: Acoustic radiation force impulse; HBV: hepatitis B virus; HCV hepatitis C virus; LSM: liver stiffness measurement; MRE: magnetic resonance elastography; N/A: not available; PHLF: post-hepatectomy liver failure; SWE: Shear wave elastography; TE: transient elastography

\section{ULTRASOUND-BASED AND OTHER IMAGING PREDICTORS}

\section{Liver stiffness measurement}

In the last few years, the liver stiffness measurement (LSM) has been proposed as a practical and widely validated surrogate of liver fibrosis and portal hypertension, able to accurately predict the risk of cirrhosis ${ }^{[79]}$, $\mathrm{CSPH}^{[80]}$ and its complications, such as the development of varices ${ }^{[81]}$ and hepatic decompensation ${ }^{[82]}$. Given that these attributes are major determinants of the risk of PHLF development, LSM has been investigated as a predictor of decompensation and other complications after hepatic resection with several methods that are mainly ultrasound-based ${ }^{[11,83-99]}$ [Table 3].

The study by Cescon et al. ${ }^{[84]}$ was one of the first papers to demonstrate that LSM, evaluated by transient elastography (TE), was an independent predictor of PHLF, together with histological cirrhosis and lower sodium levels. Since then, numerous studies have confirmed that LSM by TE is an important prognostic preoperative variable that is able to stratify the risk of decompensation, PHLF and overall complications after liver resection ${ }^{[83,93,94,96,100]}$. Different cut-offs have been proposed for this purpose, ranging from 9.7 to 22 $\mathrm{kPa}^{[93,94]}$, which correspond to current cut-offs for advanced chronic liver disease and CSPH respectively ${ }^{[80]}$. Positive findings have also been described for LSM evaluated by other elastosonography techniques. For instance, Hu et al. ${ }^{[97]}$ developed and validated a nomogram including LSM assessment by shear-wave elastography, which is able to accurately predict the risk of any grade of PHLF (c-statistic 0.825). More recently, Sato et al ${ }^{[98]}$ reported in a series of 96 consecutive patients who underwent liver resection, that LSM by magnetic resonance elastography (MRE), with a best-cut-off of $4.3 \mathrm{kPa}$, was an independent predictor of major surgical complications. When compared to other indices of portal hypertension, the accuracy of LSM was found to be non-inferior to that of the gold standard, hepatic venous pressure gradient (HVPG) ${ }^{[93]}$, and superior to that of ICG-r $15^{[83]}$ Some preliminary studies have reported a promising role of the spleen stiffness measurement $(\mathrm{SSM})^{[12,77]}$, which is known to be a more accurate surrogate of portal hypertension ${ }^{[101]}$ but its prognostic role and accuracy in this context have yet to be established. 
All the above-mentioned evidence supports the fact that LSM provides valuable prognostic information in patients undergoing liver resection ${ }^{[102]}$. Indeed, in the last European guidelines on HCC, LSM was included among the pre-operative tools to assess liver reserve before surgery. However, most of the prognostic models including LSM have not been validated externally, the proposed cut-offs differ among studies and differ too, for the elastosonography technique applied. Therefore, LSM is still not routinely used in pre-operative risk stratification of patients undergoing surgery.

Noteworthy, in none of these studies was age an independent predictor of PHLF. However, a recent paper showed that the risk of PHLF development after right hepatectomy rapidly increased in patients over 75 (incidence $35 \%>75$ years $v s .7 \%<75$ years, $\mathrm{OR}=8.8,95 \% \mathrm{CI}: 3.6-21)^{[103]}$. Considering that older age is a known risk factor for unreliable LSM measurement ${ }^{[104,105]}$ and that this category of patients might have been underrepresented in the previously published cohorts, future studies are needed to investigate the prognostic role of LSM in elderly patients undergoing liver resection.

\section{Computed tomography}

Several computed tomography (CT) signatures have been reported in association with PHLF ${ }^{[106,107]}$. With regard to liver volumetry, this is performed using CT imaging, preferably utilizing the images obtained during the venous phase. Liver volumetry is obtained by contouring the liver boundaries and segments, with semi-automated methods or manually, on dedicated software. PHLF occurrence is closely related to the volume and functional capacity of the remnant liver. Patients with a small future liver remnant (FLR) are at higher risk of developing PHLF. Shoup et al. ${ }^{[108]}$ demonstrated that the remnant liver volume (RLV) correlates with post-operative prothrombin time and bilirubin levels. In their analysis, a RLV $<25 \%$ was more predictive of PHLF than the anatomical extent of resection ${ }^{[108]}$. There is no consensus about "how much is enough" but, in general, a FLR of about $20 \%-30 \%$ has been reported as representing the limit of safety in hepatectomy, in non-cirrhotic livers, by some authors ${ }^{[109-112]}$.

Remnant liver function, estimated with CT volumetry, is reliable only when liver function is assumed homogeneous in the entire organ ${ }^{[113]}$. In cirrhotic patients, the small liver volume suggests the severity of cirrhosis and poor function of the liver. Indeed, cirrhotic livers have lower levels of hepatocyte growth factor and slower and less complete regeneration, compared with non-cirrhotic livers ${ }^{[114]}$. Therefore, in these patients, the hepatectomy-associated risk cannot be accurately determined with volumetry alone. In different published series, the critical minimum FLR for a safe hepatectomy was estimated to be approximately $40 \%$ in patients with cirrhosis ${ }^{[115,116]}$.

Spleen Volume (Sp) can also be a critical factor for the outcome of patients undergoing major liver resection. An increased Sp/RLV ratio (> 0.199) correlates with PHLF $^{[114]}$.

Another imaging pre-operative evaluation that should be assessed is the quantification of hepatic steatosis, which is shown on pre-contrast CT images as lower attenuation of the liver than that of the spleen ${ }^{[117]}$. Steatosis contributes to post-operative liver dysfunction, especially in diabetic patients and in patients with chemotherapy-associated steatohepatitis undergoing major hepatic resection ${ }^{[117]}$. The effect of steatosis is explained by the higher incidence of ischemia-reperfusion injury due to altered sinusoidal microcirculation. A recent study found a significantly higher incidence of hepatic decompensation, 90-day post-operative morbidity and surgical hepatic complications in patients with steatohepatitis than in patients without ${ }^{[118]}$.

Among other conditions that could be associated with older age and contribute to the development of PHLF, it is widely known that primary sarcopenia is strongly associated with age. Therefore, elderly patients have less skeletal muscle mass than younger patients ${ }^{[119,120]}$ and this loss of muscle mass is accelerated due to chronic medical illnesses and malnutrition ${ }^{[121]}$. At the same time, nutritional status is a major concern 
in liver disease. Cirrhotic patients often develop protein-energy malnutrition (PEM), as a result of poor dietary intake, malabsorption, increased intestinal protein loss, decreased hepatic protein synthesis, abnormal substrate utilization and hypermetabolism ${ }^{[122]}$. Malnutrition in liver disease is also associated with worse outcomes, increased complications and mortality ${ }^{[123,124]}$, and leads to a high prevalence of secondary sarcopenia ${ }^{[125]}$.

Muscular mass can be evaluated by CT, using different methods such as calculating the area $\left(\mathrm{cm}^{2}\right)$ and density of the psoas muscle at the level of the third lumbar vertebrae, or calculating the ratio between the muscular surface area (external and internal oblique, transverse, psoas and paravertebral muscles) and the square of height ${ }^{[126]}$.

Recent studies have investigated the effect of sarcopenia on the morbidity of patients undergoing liver surgery, both in cases of colon cancer metastases and of HCC. They have shown that sarcopenia is an independent risk factor for increased post-operative morbidity ${ }^{[120,121,127-129]}$. Indeed, sarcopenia is associated with a lower functional liver reserve; therefore, the average RLV of sarcopenic patients is statistically and significantly less than that of non-sarcopenic patients ${ }^{[130]}$. Obese patients can also be sarcopenic if they have increased fatty mass $(\mathrm{BMI} \geq 30)$ but a loss of muscular mass ${ }^{[131]}$. Peng et al ${ }^{[121]}$ showed that sarcopenic obesity multiplied the risk of major complications five-fold after hepatectomy in patients with liver metastases.

In addition, on $\mathrm{CT}$, is possible to calculate the intra-muscular adipose tissue content (IMAC) at the level of $\mathrm{L} 3$ (i.e., IMAC $=\mathrm{CT}$ attenuation value of the multifidus muscles $[\mathrm{HU}] / \mathrm{CT}$ attenuation value of the subcutaneous fat $[\mathrm{HU}])$. A recent paper demonstrated that muscle steatosis is associated with significantly lower overall survival and recurrence-free survival, and it is an independent risk factor for increased major post-operative complications in patients undergoing hepatectomy for HCC. Moreover, patients with high IMAC are older and have a higher mass index ${ }^{[132]}$.

Another comorbidity parameter that can be evaluated with pre-operative CT scan is the bone mineral density (BMD), which is classically defined as a "T-score", evaluated by dual X-ray absorptiometry (DXA) of the spine or hip. Of note, BMD has a significant negative correlation with age, especially in female patient ${ }^{[67]}$. Sharma et al. ${ }^{[133]}$ reported BMD by measuring the CT attenuation of the trabecular bone of the eleventh thoracic vertebral body and found that $\mathrm{BMD}<160 \mathrm{HU}$ was an independent predictor of post-liver transplant mortality in HCC patients. Miyachi et al. ${ }^{[134]}$ demonstrated however, that low BMD $(<160 \mathrm{HU})$ has a strong correlation with a poor outcome post-hepatectomy only for male patients. Thus, it is possible to utilize perioperative imaging parameters to assess the future liver remnant and the remnant liver volume, which are strictly correlated with the risk of PHLF; other imaging parameters associated with both the elderly and the health status of the patient, such as the presence of sarcopenia and low bone mineral density, are also associated with PHLF.

\section{Magnetic resonance imaging}

Both CT and magnetic resonance imaging (MRI) show excellent accuracy and quantification of hepatic volume ${ }^{[106]}$. Volumetry assessment by MRI is preferable to be performed on the hepato-biliary phase (HBP, about $30 \mathrm{~min}$ after hepatospecific contrast agent injection). Diffusion Weighted Imaging (DWI) measures the apparent diffusion coefficient (ADC) of water, a parameter that is dependent on tissue structure ${ }^{[135]}$. Several reports suggest a lower ADC value in cirrhosis than in normal livers ${ }^{[136,137]}$, probably due to the restricted water diffusion in fibrotic tissue. Chuang et al. ${ }^{[114]}$ reported that pre-operative liver ADC values $\leq 1.34 \times 10^{-3}$ significantly predicted PHLF in patients undergoing hepatectomy.

The administration of hepato-specific contrast agents can help the radiologist and the clinician to evaluate the liver's reserve function and thus, predicts the occurrence of PHLF. Gadolinium, Gd-EOB-DTPA is a hepato- 
specific contrast agent that shows up to $50 \%$ hepatocyte uptake and is then excreted into the bile ducts. In non-cirrhotic livers, it has peak enhancement on T1-W images at about 20-30 min after injection ${ }^{[138,139]}$. Uptake and metabolism of this contrast agent is related to hepatocyte function ${ }^{[140,141]}$. Therefore, hepatic parenchymal enhancement is affected by the severity of cirrhosis ${ }^{[138]}$. The mean signal intensity (SI) of liver parenchyma on HBP reflects a quantitative measure of hepatocyte contrast agent uptake ${ }^{[114]}$. Watanabe et $a l^{[142]}$ found that liver SI on Gd-EOB-DTPA MRI is strongly correlated with fibrosis stage and concluded that it is more reliable for staging hepatic fibrosis than DWI or hematologic and clinical parameters. Moreover, many recent studies ${ }^{[143,144]}$ have reported the usefulness of relative liver enhancement [RLE $=($ SI HBP - SI PRE)/SI PRE] in predicting PHLF in patients with hepatic metastases or with HCC because of the superiority of pre-operative RLE over both the 50-50 criteria and ISGLS grading system ${ }^{[67,143]}$. Pre-operative RLE measurement is considered reliable and reproducible with high inter-observer variability ${ }^{[145]}$. However, further studies are necessary to understand the real role of RLE to predict PHLF.

Other parameters derived from Gd-EOB-DTPA MRI have been evaluated as predictors of PHLF with modest success. Contrast enhancement ratio $(\mathrm{CER}=[($ SIHBP - SIPRE $) /($ SITP - SIPRE $]$ where SITP is measured on transitional phases, about 3 min post-contrast injection) is less affected by the hemodynamics of a patient than RLE, and better reflects Gd-EOB-DTPA uptake by hepatocytes. CER can also be multiplied by TLV/ SLV ratio (total CER, tCER) and by RLV/SLV ratio (remnant CER, rCER) ${ }^{[138]}$. A recent study demonstrated that rCER correlates with the development of PHLF better than volumetry (cut off $\leq 1.23$ ) and that tCER is an independent predictive factor for PHLF (cut off $\leq 1.42)^{[114]}$. The prognostic value of CER, in predicting PHLF, seems to be stronger than the ADC value and TVL/SLV ratio in cirrhotic patients ${ }^{[114]}$. Therefore, patients with a relatively small tCER should preferably go under local treatment rather than resection ${ }^{[114]}$. Asenbaum et al. ${ }^{[146]}$ combined functional and morphological parameters (functional FLR, functFLR) by measuring remnant RLE on Gd-EOB-DTPA MRI and the RLV by the formula: (RLV*remnantRLE)/body weight (BW). A decreased functFLR $(<8.73 \mathrm{~mL} / \mathrm{kg})$ demonstrated a strong correlation with the development of PHLF in patients that underwent major liver resection ${ }^{[146]}$.

Kim et al. ${ }^{[67]}$ verified the correlation between the remnant hepatocellular uptake index (rHUI $=\mathrm{RVL} \times[(\mathrm{L} 20 /$ S20)-1]) and PHLF, where L20 is the mean SI of the FLR, and S20 is the mean SI of the spleen on HBP images. A lower rHUI $(<0.89)$ and a lower body weighted and corrected rHUI (rHUI-BW < 12.38) showed a statistically significant correlation with the development of PHLF in patients undergoing major liver resection, and predicted PHLF better than ICG related parameters. In this study, the severity of PHLF also showed a statistically significant association with $\mathrm{rHUI}-\mathrm{BW}^{[67]}$. Nevertheless, despite numerous promising findings, MRI still represents an expensive, not immediate and not widely available technique, and careful evaluation about its use needs to be performed according to each hospital setting. Thus, pre-operative MRI parameters could be useful in predicting PHLF when available, otherwise, cheaper and faster techniques should be used.

\section{Single photon emission computed tomography}

Single photon emission computed tomography (SPECT) using 99 metastable technetium diethylenetriaminepentaacetic acid-galactosyl human serum albumin (99mTc-GSA) is of increasing interest for the preoperative evaluation of cirrhotic patients. The molecule 99mTc-GSA is taken up rapidly by the liver, reflecting accurately the volume of functional liver and FLR; indeed, it is correlated to bilirubin levels, INR, and ICG clearance $^{[147]}$. Liver 99mTc-GSA SPECT has been reported to be more useful than CT in predicting remnant liver function before hepatic resection ${ }^{[148]}$. This technique is thought to be a substitute for ICG rate. It can be used for patients whose liver function cannot be fully estimated using multimodal algorithms, such as patients with jaundice, portal hypertension, or ICG intolerance ${ }^{[149]}$. However, as for MRI, there has not been real-life application of this technique for predicting PHLF to date. 


\section{Interventional radiology}

Portal vein embolization (PVE) is an interventional radiological procedure. It consists of embolization of portal branches in the future resected liver, thus shifting blood flow to the FLR, allowing its hypertrophy before major hepatectomy. By increasing the volume of FLR, the risk for PHLF is decreased, even after extended liver resection ${ }^{[117]}$. Furthermore, preoperative PVE reduces intra-operative hepatocyte injury caused by the sudden increase in portal pressure at resection. Current guidelines recommend PVE for cirrhotic patients and an estimated FLR of $\leq 40 \%$, or normal patients with an intended FLR of $<20 \%{ }^{[150]}$.

CT volumetry should be performed 3-4 weeks after PVE to assess the degree of hypertrophy, which if $>5 \%$, is associated with improved patient outcomes ${ }^{[115]}$. A study by Capussotti et al. ${ }^{[151]}$ reported a FLR hypertrophy of $30 \%-40 \%$ in $4-6$ weeks in more than $80 \%$ of patients, and was therefore able to prepare patients for hepatectomy after that period. Hepatic arterial buffer response, after reduction of portal blood flow postPVE, can increase the size of the tumor. However, PVE preceded by trans-arterial chemoembolization (TACE) may prevent this by causing tumour necrosis ${ }^{[152]}$. RLE on Gd-EOB-DTPA-MRI has also been evaluated both pre- and post-PVE. In particular, the corresponding increase in RLE of the remnant liver at 14 and 28 days after PVE is significantly lower in patients who develop PHLF than in those who do not. Similar results were found comparing patients without or with mild PHLF versus those with severe PHLF ${ }^{[67]}$.

\section{CONCLUSION}

PHLF is still an event associated with major concerns by surgeons, especially in elderly patients. Several attempts have been made to identify the best non-invasive predictor of PHLF, in order to introduce a preoperative tool for the assessment of such risk in routine clinical practice. Particularly, and when available, imaging parameters allow the identification of peri-operative risk factors related to the underlying cirrhosis, the volume of the liver remnant and patient related characteristics, mainly associated with the elderly such as sarcopenia and low bone mineral density. Otherwise, in other settings, LSM as well as ICG-r15 and the ALBI score are useful NITs able to mirror hepatic dysfunction and portal hypertension, and are thus being recommended before surgery for PHLF risk assessment. However, there is still poor evidence for their application in older patients. Further prospective and well-designed studies evaluating the ability of these NITs in predicting PHLF in the elderly are thus needed.

\section{DECLARATIONS}

\section{Authors' contributions}

Conceptualized and designed the review: Marasco G, Colecchia A

Wrote, reviewed and edited the manuscript: Marasco G, Milandri M, Rossini B, Alemanni LV, Dajti E, Ravaioli F

Provided the tables: Alemanni LV, Dajti E

Reviewed and approved the final manuscript as submitted: Colecchia A, Renzulli M, Golfieri R, Festi D

Read and approved the final manuscript: All authors

\section{Availability of data and materials}

Not applicable.

\section{Financial support and sponsorship}

None.

\section{Conflicts of interest}

All authors declared that there are no conflicts of interest.

\section{Ethical approval and consent to participate}

Not applicable. 


\section{Consent for publication}

Not applicable.

\section{Copyright}

(c) The Author(s) 2020.

\section{REFERENCES}

1. Therapy S, Resection L. Hepatocellular carcinoma (liver cancer) therapy. Johns Hopkins; 2012. pp. 2-9.

2. Dufour JF, Greten TF, Raymond E, Roskams T, De T, et al. Clinical practice guidelines EASL - EORTC clinical practice guidelines: management of hepatocellular carcinoma European organisation for research and treatment of cancer. J Hepatol 2012;56:908-43.

3. Cucchetti A, Ercolani G, Vivarelli M, Cescon M, Ravaioli M, et al. Is portal hypertension a contraindication to hepatic resection? Ann Surg 2009;250:922-8.

4. Anna Elisabetta Brunetti S, Francesco Fiore Gennaro Daniele Radiologia Interventistica -Istituto Nazionale Tumori E, Pascale F, Sperimentazioni cliniche -Istituto Nazionale Tumori -Napoli, Giuseppe Cabibbo -Napoli, Casadei Gardini A, et al. Coordinatore Bruno Daniele UOC Oncologia-Ospedale del Mare-Napoli. 2018. Available from: https:/www.aiom.it/wp-content/uploads/2018/11/2018 LG AIOM_Epatocarcinoma.pdf

5. Zhang ZQ, Xiong L, Zhou JJ, Miao XY, Li QL, et al. Ability of the ALBI grade to predict posthepatectomy liver failure and long-term survival after liver resection for different BCLC stages of HCC 11 Medical and Health Sciences 1112 Oncology and Carcinogenesis World J Surg Oncol 2018;16.

6. Balzan S, Belghiti J, Farges O, Ogata S, Sauvanet A, et al. The "50-50 Criteria" on postoperative day 5 an accurate predictor of liver failure and death after hepatectomy. Ann Surg 2005;242:824-9.

7. Rahbari NN, Garden OJ, Padbury R, Brooke-Smith M, Crawford M, et al. Posthepatectomy liver failure: a definition and grading by the international study group of liver surgery (ISGLS). Surgery 2011;149:713-24.

8. Wang YY, Zhao XH, Ma L, Ye JZ, Wu FX, et al. Comparison of the ability of Child-Pugh score, MELD score, and ICG-R15 to assess preoperative hepatic functional reserve in patients with hepatocellular carcinoma. J Surg Oncol 2018;118:440-5.

9. Schneider PD. Preoperative assessment of liver function. Surg Clin North Am 2004;84:355-73.

10. Bosch J, Abraldes JG, Berzigotti A, García-Pagan JC. The clinical use of HVPG measurements in chronic liver disease. Nat Rev Gastroenterol Hepatol 2009;6:573-82.

11. Cucchetti A, Cescon M, Colecchia A, Neri F, Cappelli A, et al. Adding liver stiffness measurement to the routine evaluation of hepatocellular carcinoma resectability can optimize clinical outcome. Eur J Ultrasound 2017;38:515-22.

12. Peng W, Li JW, Zhang XY, Li C, Wen TF, et al. A novel model for predicting posthepatectomy liver failure in patients with hepatocellular carcinoma. PLoS One 2019;14:e0219219.

13. Cucchetti A, Cescon M, Golfieri R, Piscaglia F, Renzulli M, et al. Hepatic venous pressure gradient in the preoperative assessment of patients with resectable hepatocellular carcinoma. J Hepatol 2016;64:79-86.

14. Zhang ZQ, Xiong L, Zhou JJ, Miao XY, Li QL, et al. Ability of the ALBI grade to predict posthepatectomy liver failure and long-term survival after liver resection for different BCLC stages of HCC. World J Surg Oncol 2018;16:208.

15. Phan K, An VVG, Ha H, Phan S, Lam V, et al. Hepatic resection for malignant liver tumours in the elderly: a systematic review and metaanalysis. ANZ J Surg 2015;85:815-22.

16. Tanaka S, Ueno M, Iida H, Kaibori M, Nomi T, et al. Preoperative assessment of frailty predicts age-related events after hepatic resection: a prospective multicenter study. J Hepatobiliary Pancreat Sci 2018;25:377-87.

17. Sterling RK, Lissen E, Clumeck N, Sola R, Correa MC, et al. Development of a simple noninvasive index to predict significant fibrosis in patients with HIV/HCV coinfection. Hepatology 2006;43:1317-25.

18. Mallet V, Dhalluin-Venier V, Roussin C, Bourliere M, Pettinelli ME, et al. The accuracy of the FIB-4 index for the diagnosis of mild fibrosis in chronic hepatitis B. Aliment Pharmacol Ther 2009;29:409-15.

19. Kim BK, Kim DY, Park JY, Ahn SH, Chon CY, et al. Validation of FIB-4 and comparison with other simple noninvasive indices for predicting liver fibrosis and cirrhosis in hepatitis B virus-infected patients. Liver Int 2010;30:546-53.

20. Wang H, Liu A, Bo W, Feng X, Hu Y, et al. Fibrosis-4 model influences results of patients with hepatocellular carcinoma undergoing hepatectomy. Biomed Res Int 2018;2018.

21. Toyoda H, Kumada T, Tada T, Kaneoka Y, Maeda A. A laboratory marker, FIB-4 index, as a predictor for long-term outcomes of hepatocellular carcinoma patients after curative hepatic resection. Surgery 2015;157:699-707.

22. Dong J, Zhang XF, Zhu Y, Ma F, Liu C, et al. The value of the combination of fibrosis index based on the four factors and future liver remnant volume ratios as a predictor on posthepatectomy outcomes. J Gastrointest Surg 2015;19:682-91.

23. Zhou P, Chen B, Miao XY, Zhou JJ, Xiong L, et al. Comparison of FIB-4 index and child-pugh score in predicting the outcome of hepatic resection for hepatocellular carcinoma. J Gastrointest Surg 2019;10-3.

24. Zhang ZQ, Yang B, Zou H, Xiong L, Miao XY, et al. ALBI/ST ratio versus FIB-4 and APRI as a predictor of posthepatectomy liver failure in hepatocellular carcinoma patients. Medicine (Baltimore) 2019;98:e15168.

25. Lok ASF, Ghany MG, Goodman ZD, Wright EC, Everson GT, et al. Predicting cirrhosis in patients with hepatitis C based on standard laboratory tests: results of the HALT-C cohort. Hepatology 2005;42:282-92.

26. Ma J, Jiang Y, Gong G. Evaluation of seven noninvasive models in staging liver fibrosis in patients with chronic hepatitis B virus 
infection. Eur J Gastroenterol Hepatol 2013;25:428-34.

27. Zhou H, Long J, Hu H, Tian CY, Lin SD. Liver stiffness and serum markers for excluding high-risk varices in patients who do not meet Baveno VI criteria. World J Gastroenterol 2019;25:5323-33.

28. Mobarak L, Omran D, Nabeel MM, Zakaria Z. Fibro markers for prediction of hepatocellular carcinoma in Egyptian patients with chronic liver disease. J Med Virol 2017;89:1062-8.

29. Forns X, Ampurdanès S, Llovet JM, Aponte J, Quintó L, et al. Identification of chronic hepatitis C patients without hepatic fibrosis by a simple predictive model. Hepatology 2002;36:986-92.

30. Bourliere M, Penaranda G, Renou C, Botta-Fridlund D, Tran A, et al. Validation and comparison of indexes for fibrosis and cirrhosis prediction in chronic hepatitis C patients: proposal for a pragmatic approach classification without liver biopsies. J Viral Hepat 2006;13:659-70.

31. Choi WM, Lee JH, Ahn H, Cho H, Cho YY, et al. Forns index predicts recurrence and death in patients with hepatitis B-related hepatocellular carcinoma after curative resection. Liver Int 2015;35:1992-2000.

32. Johnson PJ, Berhane S, Kagebayashi C, Satomura S, Teng M, et al. Assessment of liver function in patients with hepatocellular carcinoma: a new evidence-based approach-the ALBI grade. J Clin Oncol 2015;33:550-8.

33. Wang J, Zhang Z, Yan X, Li M, Xia J, et al. Albumin-Bilirubin (ALBI) as an accurate and simple prognostic score for chronic hepatitis B-related liver cirrhosis. Dig Liver Dis 2019;51:1172-8.

34. Wan SZ, Nie Y, Zhang Y, Liu C, Zhu X. Assessing the prognostic performance of the Child-Pugh, model for end-stage liver disease, and albumin-bilirubin scores in patients with decompensated cirrhosis: a large asian cohort from gastroenterology department. Dis Markers 2020;2020:5193028

35. Zou D, Qi X, Zhu C, Ning Z, Hou F, et al. Albumin-bilirubin score for predicting the in-hospital mortality of acute upper gastrointestinal bleeding in liver cirrhosis: a retrospective study. Turkish J Gastroenterol 2016;27:180-6.

36. Xu YX, Wang YB, Tan YL, Xi C, Xu XZ. Prognostic value of pretreatment albumin to bilirubin ratio in patients with hepatocellular cancer: a meta-analysis. Medicine (Baltimore) 2019;98:e14027.

37. Zou H, Yang X, Li QL, Zhou QX, Xiong L, et al. A comparative study of albumin-bilirubin score with Child-Pugh score, model for endstage liver disease score and indocyanine green R15 in predicting posthepatectomy liver failure for hepatocellular carcinoma patients. Dig Dis 2018;36:236-43.

38. Toyoda H, Lai PBS, O’Beirne J, Chong CC, Berhane S, et al. Long-term impact of liver function on curative therapy for hepatocellular carcinoma: application of the ALBI grade. Br J Cancer 2016;114:744-50.

39. Wang YY, Zhong JH, Su ZY, Huang JF, Lu SD, et al. Albumin-bilirubin versus Child-Pugh score as a predictor of outcome after liver resection for hepatocellular carcinoma. Br J Surg 2016;103:725-34.

40. Ke M, Xu T, Li N, Ren Y, Shi A, et al. Prognostic nutritional index predicts short-term outcomes after liver resection for hepatocellular carcinoma within the Milan criteria. Oncotarget 2016;7:81611-20.

41. Andreatos N, Amini N, Gani F, Margonis GA, Sasaki K, et al. Albumin-bilirubin score: predicting short-term outcomes including bile leak and post-hepatectomy liver failure following hepatic resection. J Gastrointest Surg 2017;21:238-48.

42. Li MX, Zhao H, Bi XY, Li ZY, Huang Z, et al. Prognostic value of the albumin-bilirubin grade in patients with hepatocellular carcinoma: validation in a chinese cohort. Hepatol Res 2017;47:731-41.

43. Russolillo N, Forchino F, Conci S, Mele C, Langella S, et al. Validation of the albumin-indocyanine green evaluation model in patients with resected hepatocellular carcinoma and comparison with the albumin-bilirubin score. J Hepatobiliary Pancreat Sci 2019;26:51-7.

44. Božin T, Mustapić S, Bokun T, Patrlj L, Rakić M, et al. Albi score as a predictor of survival in patients with compensated cirrhosis resected for hepatocellular carcinoma: exploratory evaluation in relationship to palbi and meld liver function scores. Acta Clin Croat 2018;57:292-300.

45. Mai RY, Wang YY, Bai T, Chen J, Xiang BD, et al. Combination of ALBI and APRI to predict posthepatectomy liver failure after liver resection for HBV-related HCC patients. Cancer Manag Res 2019;11:8799-806.

46. De Gasperi A, Mazza E, Prosperi M. Indocyanine green kinetics to assess liver function: ready for a clinical dynamic assessment in major liver surgery? World J Hepatol 2016;8:355-67.

47. Levesque E, Martin E, Dudau D, Lim C, Dhonneur G, et al. Current use and perspective of indocyanine green clearance in liver diseases. Anaesth Crit Care Pain Med 2016;35:49-57.

48. Lisotti A, Azzaroli F, Buonfiglioli F, Montagnani M, Cecinato P, et al. Indocyanine green retention test as a noninvasive marker of portal hypertension and esophageal varices in compensated liver cirrhosis. Hepatology 2014;59:643-50.

49. Kim HJ, Kim CY, Park EK, Hur YH, Koh YS, et al. Volumetric analysis and indocyanine green retention rate at 15 min as predictors of post-hepatectomy liver failure. HPB 2015;17:159-67.

50. Cheung TT, Chan SC, Chok KSH, Chan ACY, Yu WC, et al. Rapid measurement of indocyanine green retention by pulse spectrophotometry: a validation study in 70 patients with Child-Pugh A cirrhosis before hepatectomy for hepatocellular carcinoma. Hepatobiliary Pancreat Dis Int 2012;11:267-71.

51. Purcell R, Kruger P, Jones M. Indocyanine green elimination: a comparison of the LiMON and serial blood sampling methods. ANZ J Surg 2006;76:75-7.

52. Lisotti A, Azzaroli F, Cucchetti A, Buonfiglioli F, Cecinato P, et al. Relationship between indocyanine green retention test, decompensation and survival in patients with Child-Pugh A cirrhosis and portal hypertension. Liver Int 2016;36:1313-21.

53. Zipprich A, Kuss O, Rogowski S, Kleber G, Lotterer E, et al. Incorporating indocyanin green clearance into the model for end stage liver disease (MELD-ICG) improves prognostic accuracy in intermediate to advanced cirrhosis. Gut 2010;59:963-8. 
54. Marie-louise L. Pind FBTKSM. Indocyanine green retention test (icg-r15) as a noninvasive predictor of portal hypertension in patients with different severity of cirrhosis. Eur J Gastroenterol 2016;28:948-54.

55. Fan ST. Liver functional reserve estimation: state of the art and relevance for local treatments. J Hepatobiliary Pancreat Sci 2010;17:3804.

56. Yau T, Tang VYF, Yao TJ, Fan ST, Lo CM, et al. Development of Hong Kong liver cancer staging system with treatment stratification for patients with hepatocellular carcinoma. Gastroenterology 2014;146:1691-700.e3.

57. Lam CM, Fan ST, Lo CM, Wong J. Major hepatectomy for hepatocellular carcinoma in patients with an unsatisfactory indocyanine green clearance test. Br J Surg 1999;86:1012-7.

58. Lau H, Man K, Fan ST, Yu WC, Lo CM, et al. Evaluation of preoperative hepatic function in patients with hepatocellular carcinoma undergoing hepatectomy. Br J Surg 1997;84:1255-9.

59. Imamura H, Sano K, Sugawara Y, Kokudo N, Makuuchi M. Assessment of hepatic reserve for indication of hepatic resection: decision tree incorporating indocyanine green test. J Hepatobiliary Pancreat Surg 2005;12:16-22.

60. Kim JM, Kwon CHD, Joh JW, Park JB, Lee JH, et al. Can the model for end-stage liver disease score replace the indocyanine green clearance test in the selection of right hemihepatectomy in Child-Pugh class A? Ann Surg Treat Res 2014;86:122-9.

61. Au KP, Chan SC, Chok KSH, Chan ACY, Cheung TT, et al. Child-Pugh parameters and platelet count as an alternative to ICG test for assessing liver function for major hepatectomy. HPB Surg 2017;2017.

62. Fung J, Poon RTP, Yu WC, Chan SC, Chan ACY, et al. Use of liver stiffness measurement for liver resection surgery: correlation with indocyanine green clearance testing and post-operative outcome. PLoS One 2013;8.

63. Kitano S, Kim YI. ICG clearance in assessing cirrhotic patients with hepatocellular carcinoma for major hepatic resection. HPB Surg 1997;10:182-3.

64. Hsia CY, Lui WY, Chau GY, King KL, Loong CC, et al. Perioperative safety and prognosis in hepatocellular carcinoma patients with impaired liver function11No competing interests declared. J Am Coll Surg 2000;190:574-9.

65. Lao XM, Zhang YQ, Lin XJ, Guo RP, Chen MS, et al. Estimation of hepatic resection volume in hepatocellular carcinoma by ICG(R15) and its relation with postoperative liver failure. Ai Zheng 2005;24:337-40.

66. Hwang S, Ha TY, Song GW, Jung DH, Ahn CS, et al. Quantified risk assessment for major hepatectomy via the indocyanine green clearance rate and liver volumetry combined with standard liver volume. J Gastrointest Surg 2015;19:1305-14.

67. Kim DK, Choi JI, Choi MH, Park MY, Lee YJ, et al. Prediction of posthepatectomy liver failure: MRI with hepatocyte-specific contrast agent versus indocyanine green clearance test. AJR Am J Roentgenol 2018;211:580-7.

68. Wang L, Xie L, Zhang N, Zhu W, Zhou J, et al. Predictive value of intraoperative indocyanine green clearance measurement on postoperative liver function after anatomic major liver resection. J Gastrointest Surg 2019; doi: 10.1007/s11605-019-04262-5.

69. Giannini E, Botta F, Borro P, Risso D, Romagnoli P, et al. Platelet count/spleen diameter ratio: proposal and validation of a non-invasive parameter to predict the presence of oesophageal varices in patients with liver cirrhosis. Gut 2003;52:1200-5.

70. Giannini EG, Zaman A, Kreil A, Floreani A, Dulbecco P, et al. Platelet count/spleen diameter ratio for the noninvasive diagnosis of esophageal varices: results of a multicenter, prospective, validation study. Am J Gastroenterol 2006;101:2511-9.

71. Ying L, Lin X, Xie ZL, Hu YP, Shi KQ. Performance of platelet count/spleen diameter ratio for diagnosis of esophageal varices in cirrhosis: a meta-analysis. Dig Dis Sci 2012;57:1672-81.

72. Ouyang GX, Zhang YM, Zhu SL, Wang P, Ren Y, et al. A novel, non-invasive model for diagnosing liver fibrosis stage in patients with hepatocellular carcinoma. Sci Rep 2018;8:13074.

73. Wai CT, Greenson JK, Fontana RJ, Kalbfleisch JD, Marrero JA, et al. A simple noninvasive index can predict both significant fibrosis and cirrhosis in patients with chronic hepatitis C. Hepatology. 2003;38:518-26.

74. Mai RY, Ye JZ, Long ZR, Shi XM, Bai T, et al. Preoperative aspartate aminotransferase-to-platelet-ratio index as a predictor of posthepatectomy liver failure for resectable hepatocellular carcinoma. Cancer Manag Res 2019;11:1401-14.

75. Kim BK, Han KH, Park JY, Ahn SH, Kim JK, et al. A liver stiffness measurement-based, noninvasive prediction model for high-risk esophageal varices in B-viral liver cirrhosis. Am J Gastroenterol 2010;105:1382-90.

76. Chon YE, Jung ES, Park JY, Kim DY, Ahn SH, et al. The accuracy of noninvasive methods in predicting the development of hepatocellular carcinoma and hepatic decompensation in patients with chronic hepatitis B. J Clin Gastroenterol 2012;46:518-25.

77. Marasco G, Colecchia A, Dajti E, Ravaioli F, Cucchetti A, et al. Prediction of posthepatectomy liver failure: role of SSM and LSPS. J Surg Oncol 2019;119:400-1.

78. Peng Y, Qi X, Guo X. Child-pugh versus MELD score for the assessment of prognosis in liver cirrhosis a systematic review and metaanalysis of observational studies. Medicine (Baltimore) 2016;95:e2877.

79. Castera L. Non-invasive tests for liver fibrosis progression and regression. J Hepatol 2016;64:232-3.

80. de Franchis R, Baveno VI Faculty. Expanding consensus in portal hypertension: report of the baveno VI consensus workshop: stratifying risk and individualizing care for portal hypertension. J Hepatol 2015;63:743-52.

81. Colecchia A, Ravaioli F, Marasco G, Colli A, Dajti E, et al. A combined model based on spleen stiffness measurement and Baveno VI criteria to rule out high-risk varices in advanced chronic liver disease. J Hepatol 2018;69:308-17.

82. Singh S, Fujii LL, Murad MH, Wang Z, Asrani SK, et al. Liver stiffness is associated with risk of decompensation, liver cancer, and death in patients with chronic liver diseases: a systematic review and meta-analysis. Clin Gastroenterol Hepatol 2013;11:1573-84.e1-2; quiz e88-9.

83. Kim SU, Ahn SH, Park JY, Kim DY, Chon CY, et al. Prediction of postoperative hepatic insufficiency by liver stiffness measurement (FibroScan ${ }^{\circledR}$ ) before curative resection of hepatocellular carcinoma: a pilot study. Hepatol Int 2008;2:471-7. 
84. Cescon M, Colecchia A, Cucchetti A, Peri E, Montrone L, et al. Value of transient elastography measured with fibroscan in predicting the outcome of hepatic resection for hepatocellular carcinoma. Ann Surg 2012;256:706-13.

85. Harada N, Shirabe K, Ijichi H, Matono R, Uchiyama H, et al. Acoustic radiation force impulse imaging predicts postoperative ascites resulting from curative hepatic resection for hepatocellular carcinoma. Surgery 2012;151:837-43.

86. Wong JSW, Wong GLH, Chan AWH, Wong VWS, Cheung YS, et al. Liver stiffness measurement by transient elastography as a predictor on posthepatectomy outcomes. Ann Surg 2013;257:922-8.

87. Zhang ZM, Zhang YM, Yao F, Yi P, Huang S, et al. Analysis on postoperative efficacy of radical hepatectomy for patients with NonHBV/HCV hepatocellular carcinoma. Asian Pac J Cancer Prev 2015;16:3479-83.

88. Nishio T, Taura K, Koyama Y, Tanabe K, Yamamoto G, et al. Prediction of posthepatectomy liver failure based on liver stiffness measurement in patients with hepatocellular carcinoma. Surgery 2016;159:399-408.

89. Chong CCN, Wong GLH, Chan AWH, Wong VWS, Fong AK, et al. Liver stiffness measurement predicts high-grade post-hepatectomy liver failure: a prospective cohort study. J Gastroenterol Hepatol 2017;32:506-14.

90. Han H, Yang J, Zhuge Y, Zhang M, Wu M. Point shear wave elastography to evaluate and monitor changing portal venous pressure in patients with decompensated cirrhosis. Ultrasound Med Biol 2017;43:1134-40.

91. Abe H, Midorikawa Y, Mitsuka Y, Aramaki O, Higaki T, et al. Predicting postoperative outcomes of liver resection by magnetic resonance elastography. Surgery 2017;162:248-55.

92. Shen Y, Zhou C, Zhu G, Shi G, Zhu X, et al. Liver stiffness assessed by shear wave elastography predicts postoperative liver failure in patients with hepatocellular carcinoma. J Gastrointest Surg 2017;21:1471-9.

93. Rajakannu M, Cherqui D, Ciacio O, Golse N, Pittau G, et al. Liver stiffness measurement by transient elastography predicts late posthepatectomy outcomes in patients undergoing resection for hepatocellular carcinoma. Surgery 2017;162:766-74.

94. Donadon M, Fontana A, Palmisano A, Viganò L, Procopio F, et al. Individualized risk estimation for postoperative morbidity after hepatectomy: the Humanitas score. HPB 2017;19:910-8.

95. Wu D, Chen E, Liang T, Wang M, Chen B, et al. Predicting the risk of postoperative liver failure and overall survival using liver and spleen stiffness measurements in patients with hepatocellular carcinoma. Medicine (Baltimore) 2017;96:e7864.

96. Lei J, Ji X, Hong J, Li W, Chen Y, et al. Prediction of posthepatectomy liver failure using transient elastography in patients with hepatitis B related hepatocellular carcinoma. BMC Gastroenterol 2017;17:171.

97. Hu H, Han H, Han XK, Wang WP, Ding H. Nomogram for individualised prediction of liver failure risk after hepatectomy in patients with resectable hepatocellular carcinoma: the evidence from ultrasound data. Eur Radiol 2018;28:877-85.

98. Sato N, Kenjo A, Kimura T, Okada R, Ishigame T, et al. Prediction of major complications after hepatectomy using liver stiffness values determined by magnetic resonance elastography. Br J Surg 2018;105:1192-9.

99. Procopet B, Fischer P, Horhat A, Mois E, Stefanescu H, et al. Good performance of liver stiffness measurement in the prediction of postoperative hepatic decompensation in patients with cirrhosis complicated with hepatocellular carcinoma. Med Ultrason 2018;20:272.

100. Huang Z, Huang J, Zhou T, Cao H, Tan B. Prognostic value of liver stiffness measurement for the liver-related surgical outcomes of patients under hepatic resection: a meta-analysis. PLoS One 2018;13:e0190512.

101. Ma X, Wang L, Wu H, Feng Y, Han X, et al. Spleen stiffness is superior to liver stiffness for predicting esophageal varices in chronic liver disease: a meta-analysis. PLoS One 2016;11:e0165786.

102. Galle PR, Forner A, Llovet JM, Mazzaferro V, Piscaglia F, et al. EASL clinical practice guidelines: management of hepatocellular carcinoma. J Hepatol 2018;69:182-236.

103. Longbotham D, Young A, Nana G, Feltbower R, Hidalgo E, et al. The impact of age on post-operative liver function following right hepatectomy: a retrospective, single centre experience. HPB (Oxford) 2020;22:151-60.

104. Şirli R, Sporea I, Bota S, Jurchiş A. Factors influencing reliability of liver stiffness measurements using transient elastography (M-probe) - Monocentric experience. Eur J Radiol 2013;82:e313-6.

105. Varbobitis IC, Siakavellas SI, Koutsounas IS, Karagiannakis DS, Ioannidou P, et al. Reliability and applicability of two-dimensional shear-wave elastography for the evaluation of liver stiffness. Eur J Gastroenterol Hepatol 2016;28:1204-9.

106. D’Onofrio M, De Robertis R, Demozzi E, Crosara S, Canestrini S, et al. Liver volumetry: is imaging reliable? Personal experience and review of the literature. World J Radiol 2014;6:62-71.

107. Cescon M, Cucchetti A, Grazi GL, Ferrero A, Viganò L, et al. Indication of the extent of hepatectomy for hepatocellular carcinoma on cirrhosis by a simple algorithm based on preoperative variables. Arch Surg 2009;144:57-63; discussion 63.

108. Shoup M. Volumetric analysis predicts hepatic dysfunction in patients undergoing major liver resection. J Gastrointest Surg 2003;7:32530 .

109. Kim HJ, Kim CY, Hur YH, Koh YS, Kim JC, et al. Comparison of remnant to total functional liver volume ratio and remnant to standard liver volume ratio as a predictor of postoperative liver function after liver resection. Korean J Hepato-Biliary-Pancreatic Surg 2013;17:143.

110. Abdalla EK, Vauthey JN, Ellis LM, Ellis V, Pollock R, et al. Recurrence and outcomes following hepatic resection, radiofrequency ablation, and combined resection/ablation for colorectal liver metastases. Ann Surg 2004;239:818-25; discussion 825-7.

111. Vauthey JN, Abdalla EK, Doherty DA, Gertsch P, Fenstermacher MJ, et al. Body surface area and body weight predict total liver volume in Western adults. Liver Transpl 2002;8:233-40.

112. Kishi Y, Abdalla EK, Chun YS, Zorzi D, Madoff DC, et al. Three hundred and one consecutive extended right hepatectomies: evaluation of outcome based on systematic liver volumetry. Ann Surg 2009;250:540-8.

113. Schindl MJ, Redhead DN, Fearon KCH, Garden OJ, Wigmore SJ, et al. The value of residual liver volume as a predictor of hepatic 
dysfunction and infection after major liver resection. Gut 2005;54:289-96.

114. Chuang YH, Ou HY, Lazo MZ, Chen CL, Chen MH, et al. Predicting post-hepatectomy liver failure by combined volumetric, functional MR image and laboratory analysis. Liver Int 2018;38:868-74.

115. Ribero D, Abdalla EK, Madoff DC, Donadon M, Loyer EM, et al. Portal vein embolization before major hepatectomy and its effects on regeneration, resectability and outcome. Br J Surg 2007;94:1386-94.

116. Guglielmi A, Ruzzenente A, Conci S, Valdegamberi A, Iacono C. How much remnant is enough in liver resection? Dig Surg 2012;29:617.

117. Kauffmann R, Fong Y. Post-hepatectomy liver failure. Hepatobiliary Surg Nutr 2014;3:238-46.

118. Reddy SK, Marsh JW, Varley PR, Mock BK, Chopra KB, et al. Underlying steatohepatitis, but not simple hepatic steatosis, increases morbidity after liver resection: a case-control study. Hepatology 2012;56:2221-30.

119. Kaido T, Hamaguchi Y, Uemoto S. Significance of preoperative sarcopenia to liver surgery. HepatoBiliary Surg Nutr 2019;8:59-62.

120. Valero V, Amini N, Spolverato G, Weiss MJ, Hirose K, et al. Sarcopenia adversely impacts postoperative complications following resection or transplantation in patients with primary liver tumors. J Gastrointest Surg 2015;19:272-81.

121. Peng PD, Van Vledder MG, Tsai S, De Jong MC, Makary M, et al. Sarcopenia negatively impacts short-term outcomes in patients undergoing hepatic resection for colorectal liver metastasis. HPB 2011;13:439-46.

122. Toshikuni N, Arisawa T, Tsutsumi M. Nutrition and exercise in the management of liver cirrhosis. World J Gastroenterol 2014;20:728697.

123. Maharshi S, Sharma BC, Srivastava S. Malnutrition in cirrhosis increases morbidity and mortality. J Gastroenterol Hepatol 2015;30:150713.

124. Buchard B, Boirie Y, Cassagnes L, Lamblin G, Coilly A, et al. Assessment of malnutrition, sarcopenia and frailty in patients with cirrhosis: which tools should we use in clinical practice? Nutrients 2020;12.

125. Sinclair M, Gow PJ, Grossmann M, Angus PW. Review article: Sarcopenia in cirrhosis - Aetiology, implications and potential therapeutic interventions. Aliment Pharmacol Ther 2016;43:765-77.

126. Chen LK, Liu LK, Woo J, Assantachai P, Auyeung TW, et al. Sarcopenia in Asia: consensus report of the Asian Working Group for Sarcopenia. J Am Med Dir Assoc 2014;15:95-101.

127. Harimoto N, Shirabe K, Yamashita YI, Ikegami T, Yoshizumi T, et al. Sarcopenia as a predictor of prognosis in patients following hepatectomy for hepatocellular carcinoma. Br J Surg 2013;100:1523-30.

128. Voron T, Tselikas L, Pietrasz D, Pigneur F, Laurent A, et al. Sarcopenia impacts on short- and long-term results of hepatectomy for hepatocellular carcinoma. Ann Surg 2015;261:1173-83.

129. Hamaguchi Y, Kaido T, Okumura S, Kobayashi A, Shirai H, et al. Preoperative visceral adiposity and muscularity predict poor outcomes after hepatectomy for hepatocellular carcinoma. Liver Cancer 2019;8:92-109.

130. Dello SAWG, Lodewick TM, Van Dam RM, Reisinger KW, Van Den Broek MAJ, et al. Sarcopenia negatively affects preoperative total functional liver volume in patients undergoing liver resection. HPB 2013;15:165-9.

131. Stenholm S, Harris TB, Rantanen T, Visser M, Kritchevsky SB, et al. Sarcopenic obesity: definition, cause and consequences. Curr Opin Clin Nutr Metab Care 2008;11:693-700.

132. Hamaguchi Y, Kaido T, Okumura S, Kobayashi A, Fujimoto Y, et al. Muscle steatosis is an independent predictor of postoperative complications in patients with hepatocellular carcinoma. World J Surg 2016;40:1959-68.

133. Sharma P, Parikh ND, Yu J, Barman P, Derstine BA, et al. Bone mineral density predicts posttransplant survival among hepatocellular carcinoma liver transplant recipients. Liver Transplant 2016;22:1092-8.

134. Miyachi Y, Kaido T, Yao S, Shirai H, Kobayashi A, et al. Bone mineral density as a risk factor for patients undergoing surgery for hepatocellular carcinoma. World J Surg 2019;43:920-8.

135. Shen YN, Zheng ML, Guo CX, Bai XL, Pan Y, et al. The role of imaging in prediction of post-hepatectomy liver failure. Clin Imaging 2018;52:137-45.

136. Taouli B, Vilgrain V, Dumont E, Daire JL, Fan B, et al. Evaluation of liver diffusion isotropy and characterization of focal hepatic lesions with two single-shot echo-planar MR imaging sequences: prospective study in 66 patients. Radiology 2003;226:71-8.

137. Ichikawa T, Haradome H, Hachiya J, Nitatori T, Araki T. Diffusion-weighted MR imaging with a single-shot echoplanar sequence: detection and characterization of focal hepatic lesions. AJR Am J Roentgenol 1998;170:397-402.

138. Tamada T, Ito K, Higaki A, Yoshida K, Kanki A, et al. Gd-EOB-DTPA-enhanced MR imaging: evaluation of hepatic enhancement effects in normal and cirrhotic livers. Eur J Radiol 2011;80:e311-6.

139. Schuhmann-Giampieri G, Schmitt-Willich H, Press WR, Negishi C, Weinmann HJ, et al. Preclinical evaluation of Gd-EOB-DTPA as a contrast agent in MR imaging of the hepatobiliary system. Radiology 1992;183:59-64.

140. Frericks BB, Loddenkemper C, Huppertz A, Valdeig S, Stroux A, et al. Qualitative and quantitative evaluation of hepatocellular carcinoma and cirrhotic liver enhancement using Gd-EOB-DTPA. AJR Am J Roentgenol. 200;193:1053-60.

141. Kukuk GM, Schaefer SG, Fimmers R, Hadizadeh DR, Ezziddin S, et al. Hepatobiliary magnetic resonance imaging in patients with liver disease: correlation of liver enhancement with biochemical liver function tests. Eur Radiol 2014;24:2482-90.

142. Watanabe H, Kanematsu M, Goshima S, Kondo H, Onozuka M, et al. Staging hepatic fibrosis: comparison of gadoxetate disodiumenhanced and diffusion-weighted MR imaging--preliminary observations. Radiology 2011;259:142-50.

143. Wibmer A, Prusa AM, Nolz R, Gruenberger T, Schindl M, et al. Liver failure after major liver resection: risk assessment by using preoperative gadoxetic acid-enhanced 3-T MR imaging. Radiology 2013;269:777-86.

144. Jin YJ, Lee SH, Cho SG, Kim JH, Lee JW, et al. Prediction of postoperative liver failure using gadoxetic acid-enhanced magnetic 
resonance imaging in patients with hepatocellular carcinoma. J Gastroenterol Hepatol 2016;31:1349-56.

145. Theilig D, Steffen I, Malinowski M, Stockmann M, Seehofer D, et al. Predicting liver failure after extended right hepatectomy following right portal vein embolization with gadoxetic acid-enhanced MRI. Eur Radiol 2019;29:5861-72.

146. Asenbaum U, Kaczirek K, Ba-Ssalamah A, Ringl H, Schwarz C, et al. Post-hepatectomy liver failure after major hepatic surgery: not only size matters. Eur Radiol 2018;28:4748-56.

147. Hoekstra LT, de Graaf W, Nibourg GAA, Heger M, Bennink RJ, et al. Physiological and biochemical basis of clinical liver function tests: a review. Ann Surg 2013;257:27-36.

148. Iimuro Y, Kashiwagi T, Yamanaka J, Hirano T, Saito S, et al. Preoperative estimation of asialoglycoprotein receptor expression in the remnant liver from CT ${ }^{99 \mathrm{~m}}$ Tc-GSA SPECT fusion images correlates well with postoperative liver function parameters. J Hepatobiliary Pancreat Sci 2010;17:673-81.

149. Okabayashi T, Shima Y, Morita S, Shimada Y, Sumiyoshi T, et al. Liver Function assessment using technetium 99m-galactosyl singlephoton emission computed tomography/CT Fusion imaging: a prospective trial. J Am Coll Surg 2017;225:789-97.

150. May BJ, Madoff DC. Portal vein embolization: rationale, technique, and current application. Semin Intervent Radiol 2012;29:81-9.

151. Capussotti L, Muratore A, Baracchi F, Lelong B, Ferrero A, et al. Portal vein ligation as an efficient method of increasing the future liver remnant volume in the surgical treatment of colorectal metastases. Arch Surg 2008;143:978-82; discussion 982.

152. Ray S, Mehta NN, Golhar A, Nundy S. Post hepatectomy liver failure - a comprehensive review of current concepts and controversies. Ann Med Surg 2018;34:4-10. 